\title{
The treatment of squamous anal carcinoma: guidelines of the Italian society of colo-rectal surgery
}

\author{
I. Giani $\cdot$ M. Mistrangelo $\cdot$ C. Fucini
}

Received: 19 July 2012/ Accepted: 1 October 2012

(C) Springer-Verlag Italia 2012

\begin{abstract}
The Italian society of colo-rectal surgery (SICCR) is dedicated to improving the study, prevention and management of the diseases of the colon, rectum and anus. One of the aims of the society is to establish guidelines to the treatment of these diseases. These guidelines are based on the international literature and on the best available evidence. Clinical practice guidelines are one of the most important instruments to provide therapeutic decision-making support, based on the best scientific evidence available at the time. Guidelines are advisory and not prescriptive, susceptible to continual variations secondary to innovations and new scientific evidence. These guidelines are a guide for all colo-rectal surgeons and physicians who approach anal cancer.
\end{abstract}

Keywords Anal cancer - Guidelines - Squamous cancer · Anal intraepithelial neoplasia $\cdot$ Radiochemotherapy

\section{Introduction}

Clinical practice guidelines are one of the most important instruments for any scientific society to provide some

I. Giani

Department of General Surgery, USL 8, Arezzo, Italy

M. Mistrangelo ( $\square)$

Department of Digestive and Colorectal Surgery, c/o Molinette Hospital, Centre of Minimal Invasive Surgery, University of Turin, Cso A.M. Dogliotti 14, 10126 Turin, Italy e-mail: mistrangelo@katamail.com; mmistrangelo3@molinette.piemonte.it

C. Fucini

Department of General and Emergency Surgery 3, Careggi Main Florence University and District Hospital,

Careggi, Florence, Italy therapeutic decision-making support, based on the best scientific evidence available at the time.

Guidelines are advisory and not prescriptive, susceptible to continual variations secondary to innovations and new scientific evidence.

Italian society of colo-rectal surgery (Società Italiana di Chirurgia Colorettale; SICCR) guidelines are intended for the use of all colo-rectal surgeons, health care professionals and patients who desire information.

\section{Methodology}

A MedLine search of English language references was performed by using the following keywords: anal cancer, anal squamous cell carcinoma, anal carcinoma, anal intraepithelial neoplasia, anal tumors, anal canal carcinoma and anal margin carcinoma.

The Cochrane library was also reviewed.

The levels of scientific evidence were adapted from Cook et al. [1].

\section{Epidemiology}

Carcinoma of the anus is a rare entity that the incidence of which has been rising over the last two decades, and which constitutes $3 \%$ of all gastrointestinal tract tumors.

In Western Europe, the average annual incidence of anal carcinoma is $1-3$ cases per 100,000 with a female prevalence (two to four times that of men [2]) and a highest incidence during the sixth and seventh decades of life [3].

The annual incidence can be up to 35 per 100,000 in men who practice anal-receptive sexual intercourse, and those who are human immunodeficiency virus (HIV) positive have twice the risk of those who are not [2]. 
In particular, squamous cell carcinoma (the other names, epidermoid or spinocellular, are no longer used) is the most common histological type of anal carcinoma and constitutes up to $80 \%$ of all malignant anal tumors [4].

The clinical presentation is non-specific and may include anorectal bleeding, soiling and pruritus. Pain and the progressive growth of an anal mass are among the presenting symptoms in only 1 of 3 cases [5].

The mass size at diagnosis is about $3-4 \mathrm{~cm} \mathrm{[6].}$

\section{Etiology}

Chromosome 11 deletions (11q22) or the short arm of chromosome 3 (3p22), environmental factors such as cigarette smoking, sexual orientation and a high number of sexual partners, anoreceptive intercourse, male homosexuality, viral infections of the anogenital area (human papillomavirus (HPV) virus type 16 and 18) and immunodeficiency are all considered as causative factors of anal cancer $[3,6,7]$.

The introduction of antiretroviral drugs has improved the life expectancy of HIV-positive patients. This has contributed to increasing the incidence of anal cancer in this population.

HPV infection (type 16 in about $87 \%$ of cases [8]) and anogenital warts are closely associated with anal cancer. Anal canal lesions are more often HPV positive than perianal lesions. Ninety-five percent of anal canal cancer in women and $83 \%$ in men is HPV positive while cancer located at the anal margin are HPV positive in only $80 \%$ of women and $28 \%$ of men [8]. Because of this high association with anal cancer, HPV is considered to be the most important causative factor much like in cases of cervical cancer [9-12].

In particular, HPV is involved in the pathogenesis of anal intraepithelial neoplasia (AIN) which progresses from dysplasia to invasive cancer. HPV type 16 seems to be associated with a higher risk of malignant transformation [13].

Other viral infections such as herpes simplex virus (HSV) have been studied but are considered to play only a marginal role in disease progression.

\section{Anatomy and histological variants of malignant tumors}

In the IUCC, American Joint Committee on Cancer (AJCC) and World Health Organization (WHO) staging systems, the anal canal is described as the last part of the gastrointestinal tract extending from the anal ring at the level of the puborectalis muscle (where the rectum enters the pelvic floor) to the anal margin that is the junction of the hair-bearing skin and the non-keratinizing squamous epithelium of the distal anal canal.

Tumors of the anal canal can present different histological features. These guidelines refer to squamous cell carcinoma (including the so-called cloacogenic variant) which constitutes $80 \%$ of all lesions of this area and derives from transitional and squamous cell epithelium. In some pathology literature, squamous cell carcinoma of the anal canal is also described according to additional histopathologic feature such as keratinization, presence of mucin and abundance of basement membrane-like material.

Less common is adenocarcinoma and mucinous adenocarcinoma of the anal glands or of fistula tracts that must be distinguished from very low rectal cancers. Other uncommon neoplasms of the anal canal include small cell carcinoma, carcinoid and other neuroendocrine tumors, malignant melanoma, squamous cell papilloma, papillary hidradenoma, keratoacanthoma, mesenchymal and neurogenic tumors, lymphoma, leiomyosarcoma and secondary tumors.

Tumors originating from the anal margin should be staged as skin cancer: they can be squamous cell cancer, basal cell cancer, Bowen's or Paget's disease.

This is an important distinction as skin cancers rarely involve lymph nodes or lead to distant metastases [14-16].

\section{Cancer of the anal canal}

\section{Diagnosis}

Patients complain of anal bleeding, pain and sensation of a mass in about $80 \%$ of cases.

A disease-specific history and physical examination are mandatory to evaluate predisposing factors, tumor extension and lymph node involvement.

Tissue biopsy is needed to establish the diagnosis. Anorectal cytology may only be used as a screening tool [17].

About $20 \%$ of patients present with synchronous nodal disease while distant metastases develop in 10-17 \% [1821]. Lesions growing above the dentate line usually metastasize to mesorectal, pararectal and retroperitoneal (paravertebral) nodes while those originating below the dentate line metastasize to inguinal and femoral lymph nodes. HIV-positive patients commonly present with palpable enlarged nodes that are found to be histologically positive only in $50 \%$ of cases.

Sentinel lymph node (SLN) biopsy of inguinal nodes has been proven to be a simple, safe and effective method for staging patients with anal cancer. Accurate detection of inguinal node metastases with this technique could obviate the need for prophylactic inguinal radiotherapy and 
eliminate related morbidity (e.g., inguinal fibrosis, external genitalia edema, lower limb lymphedema, osteonecrosis of femoral head, small bowel injury) which subsequently develops in $33 \%$ of irradiated patients [22].

(Level of Evidence: III; Grade of Recommendation: B).

During the diagnostic work up, endoscopic and radiologic evaluation should be performed. Colonoscopy is indicated in patients at risk for large bowel cancer and in Paget's perianal disease.

Endoanal ultrasound is useful in assessing sphincter involvement, tumor extension and local lymph node metastases. Endoanal ultrasound tumor-node-metastasis (uTNM) staging system was introduced in 2002 [23].

Nowadays, only a few studies with small numbers have evaluated the role of endoanal ultrasound in anal cancer staging. To date its main role is follow-up evaluation of patients treated with chemoradiotherapy (CRT) for squamous cell tumor of the anal canal [24]. EUS staging of anal canal cancer is reported in Table 1.

Computed tomography (CT) scanning should be performed in the pretreatment evaluation of anal cancer to exclude metastatic disease. Positron emission tomography (PET) scanning as an adjunct to CT identifies sites of metastasis not observed on CT in $25 \%$ of cases [25]. Almost $20 \%$ of patients with inguinal nodes that are negative on both physical examination and CT scan are positive on PET [26].

$\mathrm{PET} / \mathrm{CT}$ proved useful in initial staging perirectal/pelvic or inguinal lymph nodes, causing a change in radiation fields in 16-35\% of patients [25-29]. However, upstaging related to lymph node metastases might have been overestimated, as up to $31 \%$ of inguinal metastases identified by PET/CT are reportedly false positives [30].

(Level of Evidence: IV; Grade of Recommendation: C).

Currently, inguinal lymph nodes are better staged by sentinel node biopsy [30].

As far as the role of virology in the diagnostic process is concerned, diagnosis of HIV and/or HPV infection do not imply a worse prognosis and therefore do not influence the treatment plan, at least for patients with a CD4 count $>200$. However, in HIV-positive patients anal cancer may be multifocal.

(Level of Evidence: IV; Grade of Recommendation: B).

Table 1 Cancer of the anal canal—endoanal ultrasound staging

uT1 (tumor confined to the submucosa)

uT2 (lesion invading the sphincter complex)

The uT2 lesions were divided into uT2a lesions (tumor invading only the internal sphincter) and uT2b lesions (tumor invading also the external sphincter)

uT3 (lesion invading through the sphincter complex into the perianal tissue) and

uT4 (tumor invading adjacent structures)
Role of screening

High-risk groups such as homosexual men, individuals who practice anal intercourse, immunodepressed individuals and women affected by cervical intraepithelial neoplasia (CIN) III should be screened for anal cancer and AIN. Screening should be performed with anal cytology and high-resolution anoscopy.

HPV infection should be considered in the evaluation of the progression of precancerous lesions such as AIN to anal cancer [13]. Due to the close relationship of cervical cancer with HPV infection, a gynecological exam should be performed with the aim of screening for synchronous cervical cancer.

Role of vaccines

Prophylactic vaccines against human papillomavirus have shown nearly $100 \%$ efficacy against high-grade lesions of the cervix, vulva and vagina in uninfected women under 26 years of age. These results suggest vaccines will have a role in the prevention of anal intraepithelial neoplasia and squamous cell carcinoma of the anus in both sexes $[31,32]$.

\section{Staging}

The most recent TNM staging version, published by the AJCC [33] is based on clinical and surgical-pathological assessment and more precisely reflects prognostic factors, specifically the size of the tumor and the regional lymphatic spread (Table 2).

\section{Treatment}

Management of anal cancer has changed during the last decades from a purely surgical approach, with a 5-year survival rate ranging from 30 to $80 \%$, to combined CRT with surgery indicated in case of residual or recurrent tumor [34]. However, no significant change in overall survival has been reported so far $[17,19,20,22]$ when this approach is compared with traditional surgery.

A local surgical approach may be appropriate only for selected small lesions and for carcinoma in situ [35]. Tumor radiation alone is at times adopted for small lesions up to T2 with the radiation dose of 40-50 Gy and can be curative in $70-80 \%$ of cases $[6,36]$.

With a radiation field extended not only to the tumor site but also to the pelvis and inguinal lymph nodes, a success rate of $60-80 \%$ can be achieved $[37,38]$. To follow are the recommendations for the treatment of the most common presentations of the disease. 
Table 2 Cancer of the anal canal

\section{The TNM system}

The TNM system for staging contains 3 key pieces of information

$\mathrm{T}$ describes the size of the primary tumor, measured in centimeters $(\mathrm{cm})$ and whether the cancer has spread to organs next to the tumor

$\mathrm{N}$ describes the extent of spread to nearby (regional) lymph nodes

$\mathrm{M}$ indicates whether the cancer has metastasized (spread) to other organs of the body

Numbers or letters appear after T, N and M to provide more details about each of these factors

The numbers 0 through 4 indicate increasing severity

The letter X means "cannot be assessed" because the information is not available

The letters "is" mean "carcinoma in situ," which means the tumor is contained within the top layer of anal tissue and has not yet reached deeper layers of tissue

The possible values for $\mathrm{T}$ are

TX: Primary tumor cannot be assessed

T0: No evidence of primary tumor

Tis: Carcinoma in situ

T1: The tumor is $2 \mathrm{~cm}$ (about $4 / 5 \mathrm{inch}$ ) across or smaller

T2: Tumor is between 2 and $5 \mathrm{~cm}$ in size (about 1-2 inches)

T3: Tumor is larger than $5 \mathrm{~cm}$

T4: Tumor of any size that is growing into nearby organ(s), such as the vagina, urethra (the tube that carries urine out of the bladder), prostate gland or bladder

The possible values for $\mathrm{N}$ are

NX: Regional lymph nodes cannot be assessed

N0: No regional lymph node spread

N1: Spread to lymph nodes near the rectum

N2: Spread to lymph nodes on one side of the groin and/or pelvis

N3: Spread to lymph nodes near the rectum and in the pelvis or groin or to both sides of the groin or pelvis

The $M$ values are

MX: Presence of distant metastasis cannot be assessed

M0: No distant spread

M1: Distant spread to internal organs or lymph nodes of the abdomen

Stage grouping

To make this information more helpful, these TNM descriptions can be grouped together into a simpler set of stages, labeled stage 0 through stage IV

Stage 0: Tis, N0, M0: Stage 0 is very early cancer (or precancer) that exists only in the top layer of anal tissue. This stage is also known as carcinoma in situ

Stage I: T1, N0, M0: The cancer cells have spread beyond the top layer of anal tissue and the tumor is no longer carcinoma in situ. The tumor is less than $2 \mathrm{~cm}$ (about $4 / 5 \mathrm{inch}$ ) in size. It has not spread to lymph nodes or distant sites

Stage II: T2 or 3, N0, M0: The cancer is larger than $2 \mathrm{~cm}$ in size, but it has not spread to nearby organs or lymph nodes. It has not spread to distant sites
Table 2 continued

Stage IIIA: (T1-3, N1, M0) or (T4, N0, M0): The cancer can be any size and either has spread to the lymph nodes around the rectum (N1) or it has grown into nearby organs (T4), such as the vagina or the bladder without spreading to nearby lymph nodes. It has not spread to distant sites

Stage IIIB: (T4, N1, M0), or (Any T, N2-3, M0): Either the cancer has grown into nearby organs, such as the vagina or the bladder, and has also spread to lymph nodes around the rectum, or it can be of any size but has spread to lymph nodes in the groin, with or without spread to lymph nodes around the rectum. It has not spread to distant sites

Stage IV: Any T, Any N, M1: The cancer has spread to distant organs or tissues. It can be any size and may or may not have spread to lymph nodes

Any $\mathrm{T}$ any $\mathrm{N}$ : polychemotherapy + radiotherapy

Radiotherapy (RT) with concurrent chemotherapy is the current standard of care for patients with localized squamous cell cancer of the anal canal.

The majority of patients treated with CRT have excellent outcomes, with 5-year overall survival rates of approximately $75 \%[15,19]$.

(Level of Evidence: I; Grade of Recommendation: A)

Since its introduction by Nigro in 1979 [39, 40] (5-Fu, mitomycin and radiation), several studies have demonstrated the greater efficacy of the association of RT with chemotherapy with lower rates of local failure and recurrence and a smaller number of patients requiring a colostomy when compared with RT alone [35].

(Level of Evidence: I; Grade of Recommendation: A).

Pelvic RT can cause late toxicity, adversely impact bowel and sexual function and adversely affect quality of life (QoL). Younger patients reported worse QoL scores.

Modern techniques of RT, such as intensity-modulated radiation therapy (IMRT), could potentially reduce toxicity by reducing the radiation dose to the anorectal region and genitalia.

The association of multiple chemotherapeutic agents with RT results in a better synergistic effect $[16,22,41]$ is currently recommended.

(Level of Evidence: I; Grade of Recommendation: A).

RT is usually delivered at a total dose varying between 45 and 59 Gy. Higher doses without prolonged breaks in treatment have been shown to be more effective. The need for a diverting colostomy increases with the increase in the RT dose. The above RT dose should ideally be delivered during a period of 6 weeks [16, 42-45].

(Level of Evidence: III; Grade of Recommendation: B).

In HIV-positive patients, a good tolerance of CRT can be predicted if the CD4 count is above 200 [46]. 
Persistent progressive or recurrent disease

Local failure occurs in up to $30 \%$ of patients and is equally divided between persistent (if the neoplasms is found up to 3 months after the end of CRT), progressive (if the neoplasm grows in size during the CRT) and recurrent (if the neoplasms reappears 3 or more months after the end of CRT).

The waiting time from the end of CRT to the final evaluation of the treatment is considered to be 8-10 weeks. The duration of the interval between CRT and final evaluation is still under debate with some authors suggesting a longer period of observation.

Persistent disease is re-evaluated at 4 weeks, then, the cases where a regression is noted are followed. Those without regression as those clearly progressing are best treated with an abdominoperineal resection (APR) which is an effective option for this indication with a 5-year survival rate of $24-58 \%$ [47].

(Level of Evidence III; Grade of Recommendation: B).

Survival after APR resection is longer for patients with persistent disease compared with patients with recurrent disease [7, 22, 47-51]. APR may also be beneficial in the treatment of local RT-induced complications such as stenosis, ulceration or incontinence. An additional boost of CRT has been suggested in a small number of reports but its efficacy is debated [17].

In case of progressive disease, no response to CRT, extrapelvic recurrence or local recurrence after APR, treatment with multiple chemotherapeutic agents is indicated $[52,53]$.

(Level of Evidence III; Grade of Recommendation: B).

Synchronous inguinal lymph node involvement completely regresses after CRT in $90 \%$ of cases [15].

Metachronous lymph node involvement, seen in $10-20 \%$ of patients, usually within 6 months from the end of treatment, may also respond to CRT [41].

In case of persistent lymph node disease, surgical removal is indicated.

\section{Follow-up}

A clinical evaluation with digital rectal examination, proctoscopy and abdominal-inguinal palpation is recommended.

Follow-up with serial endoanal ultrasound has recently gained popularity but the results are still preliminary [23, 24].

(Level of Evidence: IV; Grade of Recommendation: B).

Follow-up begins at 6-12 weeks after the end of CRT and needs to be repeated every 3-6 months. Endorectal ultrasound (ERUS) and CT scan indicated in case recurrence are suspected [7, 54-56].

The proposed flow chart showing the diagnostic and therapeutic algorithm for anal canal cancer is reported in Table 3.

\section{Anal margin}

Diagnosis

It may be difficult to differentiate between anal margin and anal canal in the case of large tumors.

The differential diagnosis between anal canal and anal margin tumors is useful because of the difference in treatment and prognosis (generally better for anal margin lesions) between the two [6].

Bowen's and Paget's diseases of the anal margin can be associated with other malignancies ( $5 \%$ for Bowen up to $50 \%$ for Paget) [6].

This extramammary form of Paget's represents less than $1 \%$ of anal disease and $6.5 \%$ of all cases of Paget's disease [6].

This tumor can recur after radical surgery and has a capacity of metastatic spread: its aggressive behavior imposes a long-term follow-up with frequent clinical, radiological and endoscopic controls.

The diagnostic work up for anal margin tumors is that the same as the one highlighted for anal canal tumors.

\section{Clinical staging}

Anal margin squamous cell carcinomas are staged like skin cancer, according to the AJCC [33].

\section{Treatment}

A local excision ( $1 \mathrm{~cm}$ margin) is indicated in early squamous lesions such as $\mathrm{T} 1, \mathrm{~N} 0,<2 \mathrm{~cm}$, microinvasive or carcinoma in situ, and well-differentiated tumors, similarly to skin lesions, with a $80 \% 5$-year survival rate [57].

In case of more extended lesions or doubtful inguinal or regional lymph nodes, adjuvant radiation therapy is suggested.

More locally advanced lesions such as T3 or T4 need to be treated with radiation of either inguinal regions or pelvis associated with chemotherapy as previously described for anal canal lesions.

A more extended surgical approach such as APR is indicated in case of CRT failure and in case of incontinent patients with large, bulky cancers infiltrating the sphincter and pelvic muscles.

The proposed flow chart showing the diagnostic and therapeutic algorithm for cancer of anal margin is reported in Table 4.

Anal intraepithelial neoplasia

AIN has been called, among other things, dysplasia, carcinoma in situ, anal squamous intraepithelial lesion, Bowen's 
Table 3 Diagnostic and therapeutic algorithm for anal canal cancer

\begin{tabular}{|c|c|}
\hline Biopsy & Histopathological diagnosis of squamous cell carcinom \\
\hline \multirow[t]{3}{*}{ Staging } & $\begin{array}{l}\text { Clinical evaluation: digital anorectal } \\
\text { evaluation }+ \text { inguinal evaluation }\end{array}$ \\
\hline & $\begin{array}{l}\text { Instrumental evaluation: chest X-ray or CT } \\
\text { scan }+ \text { anoscopy }+ \text { pelvic MRI or CT scan or } \\
\text { PET-CT; eventual sentinel lymph node biopsy }\end{array}$ \\
\hline & $\begin{array}{l}\text { HIV test and CD4 count }+ \text { gynecological exam } \\
\text { (screening for cervical cancer) }\end{array}$ \\
\hline Treatment & $\begin{array}{l}\text { Any } \mathrm{T} \text { any } \mathrm{N} \text { : polychemotherapy }+ \text { radiotherapy } \\
\text { Evaluate in } 8-12 \text { weeks }\end{array}$ \\
\hline \multicolumn{2}{|c|}{$\begin{array}{l}\text { Complete remission: evaluation every } 3-6 \text { months for } 5 \text { years } \\
\text { (clinical }+ \text { radiological evaluation) }\end{array}$} \\
\hline \multicolumn{2}{|c|}{ Local recurrence: abdominoperineal resection } \\
\hline \multicolumn{2}{|c|}{ Distant metastasis: polychemotherapy or clinical trial } \\
\hline \multicolumn{2}{|c|}{$\begin{array}{l}\text { Persistent disease-histopathological confirmation: re-evaluation at } \\
4 \text { weeks }\end{array}$} \\
\hline \multicolumn{2}{|c|}{ No regression or progression: treatment as a progressive disease } \\
\hline \multicolumn{2}{|c|}{ Regression: evaluate in 2 months } \\
\hline \multicolumn{2}{|c|}{$\begin{array}{l}\text { Progressive disease-histopathological confirmation: } \\
\text { abdominoperineal resection } \pm \text { then follow-up }\end{array}$} \\
\hline
\end{tabular}

disease. It has some characteristics in common with CIN and in fact is classified according to cervical cytology.

High-grade anal intraepithelial neoplasia, also referred to as anal squamous carcinoma in situ, or Bowen's disease of the anus, make up less than $1 \%$ of all digestive system cancers.

They can be accidentally found in the anal transitional area as in the anal margin area.

AIN is considered as a precursor to anal squamous cell carcinoma: AIN Grade 1 correspond to low-grade squamous intraepithelial lesion (LSIL), AIN II-III stands for high-grade squamous intraepithelial lesion (HSIL) that is sometimes referred to as anal carcinoma in situ and Bowen's disease.

Up to $80 \%$ of AIN are believed to develop from HPV 16 and 18 infections.

\section{Diagnosis}

Incidentally diagnosed, they can present as an eczematoid area with papules, often white, irregular and fissured.

A high-level suspicious history should be taken, with particular attention to signs, symptoms and predisposing factors.

Basic diagnostic work up includes clinical inspection of the perianal area, digital rectal examination, and anal cytology.

These lesions are more common in HIV patients, especially in HIV-positive men having sex with men (MSM).

A compromised immune system, both in male and in female is an important risk factor.
HIV seropositivity, like immunosuppression for organ transplantation or for specific diseases, is associated with AIN and its progression to high-grade squamous intraepithelial lesions. This progression has been observed to occur in about $10-50 \%$ of HIV-positive patients within 2 years [58, 59].

HPV infection associated with AIN is well demonstrated. Despite the limited data available about the pathophysiologic effects of HPV (subtypes 16 and 18), a loss of tumor suppressor protein $\mathrm{p} 53$ has been described as well as some gene aberrations and alterations [58].

These associations can be simply superimposed with cervical cancer natural history [60-62].

As reported for CIN, Papanicolaou smear cytological examination can be used for screening and follow-up of AIN.

(Level of Evidence III; Grade of Recommendation: C).

Nevertheless, high-resolution anoscopy-directed biopsy is still considered as the gold standard for AIN diagnosis.

\section{Treatment}

The treatment of choice is surgical resection with anal mapping.

Although the main treatment modality for treating persistent/recurrent AIN is surgery, an alternative approach using external beam radiation has been proposed.

As a well-established precursor of squamous cell carcinoma, AIN observation is not considered an appropriate strategy [63].

(Level of Evidence: IV; Grade of Recommendation: C).

New drugs with an immunomodulatory effect, such as $5 \%$ imiquimod cream (response rate more than $50 \%$ ) [64] or chemotherapeutics such as $5 \% 5$-fluorouracil cream (initial response rate of $90 \%$ ) are indicated for AIN [65].

(Level of Evidence: IV; Grade of Recommendation: C).

Photodynamic therapy has been suggested in some cases, but its effectiveness has been shown only in case reports [66].

(Level of Evidence: V; Grade of Recommendation: D).

Surgical excision (wide local excision, targeted destruction, infrared coagulation) and careful clinical follow-up similar to what is indicated for CIN have been adopted to treat AIN and to prevent its progression [67-70].

(Level of Evidence: III; Grade of Recommendation: C).

\section{Follow-up}

Considering the risk of progression to squamous cell carcinoma, surveillance is mandatory.

This can be performed at 6-month follow-up unless dysplasia is still present. High-resolution anoscopy with magnification and/or the application of Lugol's solution can be performed especially in those patients with risk factors [70]. 
Table 4 Diagnostic and therapeutic algorithm for anal margin cancer

Biopsy Histopathological diagnosis of squamous cell carcinoma

Staging Clinical evaluation: digital anorectal evaluation + inguinal evaluation

Instrumental evaluation: chest X-ray or CT scan + anoscopy + pelvic MRI or CT scan or PET$\mathrm{CT}$; eventual sentinel node biopsy

HIV test and CD4 count + gynecological exam (screening for cervical cancer)

Treatment $\mathrm{T} 1, \mathrm{~N} 0<2 \mathrm{~cm}$, microinvasive or carcinoma in situ, well differentiated: local excision with $1 \mathrm{~cm}$ margin

$\mathrm{T} 2-4$, any N: polychemotherapy + radiotherapy + evaluate in $8-12$ weeks

Complete remission: evaluation of every 3-6 months for 5 years

(clinical + radiological evaluation)

Local recurrence: abdominoperineal resection

Distant metastasis: polychemotherapy or clinical trial

Progressive disease-histopathological confirmation:

abdominoperineal resection \pm polychemotherapy $+\mathrm{RT}$ - then

follow-up

Persistent disease—histopathological confirmation: re-evaluation at 4 weeks

No regression-progression: treatment as a progressive disease

Regression: evaluate in 2 months

(Level of Evidence: III; Grade of Recommendation: B).

The proposed flow chart showing the diagnostic and therapeutic algorithm for AIN is reported in Table 5.

\section{Verrucous carcinoma}

This tumor, also called giant condyloma (BuschkeLowenstein tumor), appears as a cauliflower-like lesion that can involve the anogenital area.

Some of these lesions are HPV positive (subtypes 6 and 11).

Intermediate between classical condyloma and squamous cell cancer, it is characterized by a local invasive behavior with a combination of exophytic and endophytic growth with very rare metastasis and a variable risk of showing malignant transformation (around $42 \%$ ) [71].

\section{Diagnosis}

It presents like an exophytic tumor of the genital or perianal area, with ulceration and sometimes fistulae and sinuses. It is more commonly seen in men than in women ( $2-3$ vs. 1$)$ and immunocompromised patients.

The histological appearance of this cancer is similar to that of condyloma acuminata, but with a tendency to compress and displace deeper tissues, without basement membrane disruption.
Table 5 Diagnostic and therapeutic algorithm for anal intraepithelial neoplasia-(AIN)

\begin{tabular}{cc}
\hline Biopsy & Histopathological diagnosis of \\
& AIN GRADE 1-low-grade squamous intraepithelial \\
& lesion (LSIL) \\
& AIN GRADE 2-high-grade squamous intraepithelial \\
& lesion (HSIL) \\
& Dysplasia, carcinoma in situ, anal squamous \\
& intraepithelial lesion, Bowen disease, etc. \\
& Anal cytology: Papanicolaou smear cytological \\
& examination \\
& Clinical evaluation: digital anorectal evaluation + \\
inguinal evaluation \\
Staging & Instrumental evaluation: high-resolution anoscopy \\
& HIV test and CD4 count + gynecological exam \\
& (screening for cervical cancer) \\
Treatment & Surgical resection with anal mapping (wide local \\
& excision, targeted destruction, infrared coagulation) \\
Complete remission: evaluation every 6 months for 5 years \\
(clinical + anoscopy evaluation) \\
Recurrent & Histopathological confirmation \\
disease & AIN: local excision and follow-up \\
& Anal margin cancer: see dedicated chapter
\end{tabular}

Physical examination and a dedicated diagnostic work up (the same as the one highlighted for anal canal and margin tumors) are useful to choose the right treatment regimen.

\section{Treatment}

A wide local excision is indicated to avoid malignant transformation, and because of the high number of recurrences.

Other treatment modalities such as chemotherapy or imiquimod may be attempted to avoid mutilating surgical interventions [72].

Follow-up

An established and rigorous follow-up is necessary because of frequent recurrences and possible malignant transformation.

\section{Conclusions}

Cancer of the anal canal is still a challenge. Despite the efficacy showed by the introduction of RT into the treatment plan, a lot of work needs to be done to better define this disease.

Conflict of interest None. 


\section{References}

1. Cook DJ, Guyatt GH, Laupacis A, Sackett DL (1992) Rules of evidence and clinical recommendations on the use of antithrombotic agents. Chest 102:S305-S311

2. Clark MA, Hartley A, Geh JI (2004) Cancer of the anal canal. Lancet Oncol 5:149-157

3. Klas J, Rothenberger D, Wong WD, Madoff R (1999) Malignant tumors of the anal canal. The spectrum of disease, treatment and outcome. Cancer 85:1686-1693

4. Minsky BD, Hoffman JP, Kelsen DP (2001) Cancer of the anal region. In: DeVita VT Jr, Hellman S, Rosenberg SA (eds) Cancer: principles \& practice of oncology, 6th edn. Lippincott-Williams \& Wilkins, Philadelphia, pp 1319-1342

5. Tanum G (1991) Diagnosis of anal carcinoma-doctor's finger still the best? Oncology 48:383-386

6. Deans GT, McAleer JJA, Spence RAJ (1994) Malignant anal tumours. Br J Surg 81:500-508

7. Ryan D, Compton C, Mayer R (2000) Carcinoma of the anal canal. N Engl J Med 342:792-800

8. Frisch M, Fenger C, van den Brule AJ et al (1999) Variants of squamous cell carcinoma of the anal canal and perianal skin and their relation to human papilloma viruses. Cancer Res 59:753-757

9. Holmes F, Borek D, Owen-Kummer M et al (1988) Anal cancer in women. Gastroenterology 95:107-111

10. Ryan DP, Mayer RJ (2000) Anal carcinoma: histology, staging, epidemiology, treatment. Curr Opin Oncol 12:345-352

11. Beckmann AM, Daling JR, Sherman KJ et al (1989) Human papillomavirus infection and anal cancer. Int $\mathrm{J}$ Cancer 43: 1042-1049

12. Williams GR, Talbot IC (1994) Anal carcinoma: a histological review. Histopathology 25:507-516

13. Palmer JG, Scholefield JH, Coates PJ et al (1989) Anal cancer and human papillomaviruses. Dis Colon Rectum 32:10161022

14. Morson BC, Sobin LH (1976) Histological typing of intestinal tumours. In International histological classification of tumors, no 15. World Health Organization, Geneva

15. Cummings BJ, Keane TJ, OSullivan B, Wong CS, Catton CN (1991) Epidermoid anal cancer: treatment by radiation alone or by radiation and 5-fluorouracil with and without mitomycin C. Int J Rad Oncol Biol Phys 21:1115-1125

16. Greene FL, Page DL, Fleming ID et al (2002) American joint committee on cancer: AJCC cancer staging manual, 6th edn. Springer, New York, pp 157-164

17. Friedlander MA, Stier E, Lin O (2004) Anorectal cytology as a screening tool for anal squamous lesions. Cancer 102:19-26

18. Gerard JP, Chapet O, Samiei F et al (2001) Management of inguinal lymph node metastases in patients with carcinoma of the anal canal: experience in a series of 270 patients treated in Lyon and review of the literature. Cancer 92:77-84

19. Arnott SJ, Cunningham D, Gallagher J et al (1996) Epidermoid anal cancer: results from the UKCCCR randomised trial of radiotherapy alone versus radiotherapy, 5-fluorouracil, and mitomycin. Lancet 348:1049-1054

20. Bartelink H, Roelofsen F, Eschwege F et al (1997) Concomitant radiotherapy and chemotherapy is superior to radiotherapy alone in the treatment of locally advanced anal cancer: results of a phase III randomized trial of the European organization for research and treatment of cancer radiotherapy and gastrointestinal cooperative groups. J Clin Oncol 15:2040-2049

21. American Joint Committee on Cancer (1997) AJCC cancer staging manual, 5th edn. Lippincott-Raven Publishers, Philadelphia

22. Mistrangelo M, Morino M (2009) Sentinel lymph node biopsy in anal cancer: a review. Gastroenterol Clin Biol 33:446-450
23. Tarantino D, Bernstein MA (2002) Endoanal ultrasound in the staging and management of squamous-cell carcinoma of the anal canal: potential implications of a new ultrasound staging system. Dis Colon Rectum 45:16-22

24. Martellucci J, Naldini G, Colosimo C, Cionini L, Rossi M (2009) Accuracy of endoanal ultrasound in the follow-up assessment for squamous cell carcinoma of the anal canal treated with radiochemotherapy. Surg Endosc 23:1054-1057

25. Cotter SE, Grigsby PW, Siegel BA et al (2006) FDG-PET/CT in the evaluation of anal carcinoma. Int J Radiat Oncol Biol Phys 65:720-725

26. Anderson C, Koshy M, Staley C et al (2007) PET-CT fusion in radiation management of patients with anorectal tumors. Int $\mathrm{J}$ Radiat Oncology Biol Phys 69:155-162

27. Nguyen BT, Joon DL, Khoo V et al (2008) Assessing the impact of FDG-PET in the management of anal cancer. Radiother Oncol $87: 376-382$

28. de Winton E, Heriot AG, Ng M et al (2009) The impact of 18-fluorodeoxyglucose positron emission tomography on the staging, management and outcome of anal cancer. Br J Cancer 100:693-700

29. Renaud S, Guillermand S, Eberlé-Pouzeratte MC et al (2009) Apport de la tomographie par émission de positrons au ${ }^{18} \mathrm{~F}-$ fluorodéoxyglucose (TEP-FDG) dans la prise en charge du cancer du canal anal. Med Nucl 33:415-424

30. Mistrangelo M, Pelosi E, Bellò M et al (2010) Comparison of positron emission tomography scanning and sentinel node biopsy in the detection of inguinal node metastases in patients with anal cancer. Int J Radiation Oncol Biol Phys 77:73-78

31. Franceschi S, De Vuyst H (2009) Human papillomavirus vaccines and anal carcinoma. Curr Opin HIV AIDS 4:57-63

32. Monsonego J (2010) Anal cancer and human papillomaviruses: a perspective based on the cervical cancer model. Gynecol Obstet Fertil 38:250-254

33. Edge SE, Byrd DR, Compton CC et al (2009) AJCC cancer staging manual, 7th edn. Springer, New York

34. Martenson JA, Gunderson LL (1993) External radiation therapy without chemotherapy in the management of anal cancer. Cancer 71:1736-1740

35. Ajani JA, Winter KA, Gunderson LL et al (2006) Intergroup RTOG 98-11: a phase III randomized study of 5-fluorouracil (5-FU), mitomycin, and radiotherapy versus 5-fluorouracil, cisplatin and radiotherapy in carcinoma of the anal canal. J Clin Oncol 24:4009

36. Faynsod M, Vargas H, Tolmos J et al (2000) Patterns of recurrence in anal canal carcinoma. Arch Surg 135:1090-1095

37. International Union Against Cancer (1987) TNM classification of malignant tumors, 4th edn. In: Hermanek P, Sobin LH (eds) Springer, New York

38. American Joint Committee on Cancer (1987) Manual for staging of cancer, 3rd edn. J B Lippincott, Philadelphia

39. Nigro ND (1987) Multidisciplinary management of carcinoma of the anus. World J Surg 11:446-451

40. Nigro ND, Vaitkevicius VK, Considine B (1974) Combined therapy for cancer of the anal canal. A preliminary report. Dis Colon Rectum 17:354-356

41. Fuchshuber PR, Rodriguez-Bigas M, Weber T, Petrelli NJ (1997) Anal canal and perianal epidermoid cancers. J Am Coll Surg 185:494-505

42. Constantinou EC, Daly W, Fung CY et al (1997) Time-dose considerations in the treatment of anal cancer. Int J Radiat Oncol Biol Phys 39:651-657

43. Touboul E, Schlienger M, Buffat L et al (1994) Epidermoid carcinoma of the anal canal. Results of curative-intent radiation therapy in a series of 270 patients. Cancer 73:1569-1579 
44. Graf R, Wust P, Hildebrandt B et al (2003) Impact of overall treatment time on local control of anal cancer treated with radiochemotherapy. Oncology 65:14-22

45. Deniaud-Alexandre E, Touboul E, Tiret E et al (2003) Epidermoid carcinomas of the anal canal treated with definitive radiation therapy in a series of 305 patients. Cancer Radiotherapie 7:237-253

46. Berry JM, Palefsky JM, Welton ML (2004) Anal cancer and its precursors in HIV-positive patients: perspectives and management. Surg Oncol Clin N Am 13:355-373

47. Papaconstantinou HT, Bullard KM, Rothenberger DA, Madoff RD (2006) Salvage abdominoperineal resection after failed Nigro protocol: modest success, major morbidity. Colorectal Dis 8: 124-129

48. Renehan AG, Saunders MP, Schofield PF, ODwyer ST (2005) Patterns of local disease failure and outcome after salvage surgery in patients with anal cancer. Br J Surg 92:605-614

49. Das P, Bhatia S, Eng C et al (2007) Predictors and patterns of recurrence after definitive chemoradiation for anal cancer. Int $\mathbf{J}$ Rad Oncol Biol Phys 68:794-800

50. Nilsson PJ, Svensson C, Goldman S, Glimelius B (2002) Salvage abdominoperineal resection in anal epidermoid cancer. Br J Surg 89:1425-1429

51. Akbari RP, Paty PB, Guillem JG et al (2004) Oncologic outcomes of salvage surgery for epidermoid carcinoma of the anus initially managed with combined modality therapy. Dis Colon Rectum 47:1136-1144

52. Carey RW (1984) Regression of pulmonary metastases from cloacogenic carcinoma after cis-platinum/5-fluorouracil treatment. J Clin Gastroenterol 6:257-259

53. Ajani JA, Carrasco CH, Jackson DE, Wallace S (1989) Combination of cisplatin plus fluoropyrimidine chemotherapy effective against liver metastases from carcinoma of the anal canal. Am J Med 87:221-224

54. Longo WE, Vernava AM, Wade TP et al (1994) Recurrent squamous cell carcinoma of the anal canal. Predictors of initial treatment failure and results of salvage therapy. Ann Surg 220: $40-49$

55. Herzog U, Boss M, Spichtin H (1998) Endoanal ultrasonography in the follow-up of anal carcinoma. Surg Endosc 8:1186-1189

56. Christensen AF, Nielsen MB, Svendsen LB, Engelholm SA (2006) Three-dimensional anal endosonography may improve detection of recurrent anal cancer. Dis Colon Rectum 49:1527-1532

57. Palefsky J, Holly EA, Hogeboom CJ et al (1998) Virologic, immunologic, and clinical parameters in the incidence and progression of anal squamous intraepithelial lesions in HIV-positive and HIV-negative homosexual men. J Acquir Immune Defic Syndr Hum Retrovirol 17:314-319

58. Ogunbiyi OA, Scholefield JH, Raftery AT et al (1994) Prevalence of anal human papillomavirus infection and intraepithelial neoplasia in renal allograft recipients. Br J Surg 81:365-367

59. Holly EA, Ralston ML, Darragh TM, Greenblatt RM, Jay N, Palefsky JM (2001) Prevalence and risk factors for anal squamous intraepithelial lesions in women. J Natl Cancer Inst 93: 843-849

60. Chin-Hong PV, Vittinghoff E, Cranston RD et al (2005) Age related prevalence of anal cancer precursors in homosexual men: the EXPLORE study. J Natl Cancer Inst 97:896-905

61. Frisch M, Glimelius B, van den Brule AJ et al (1997) Sexually transmitted infection as a cause of anal cancer. N Engl J Med 337:1350-1358

62. Chang GJ, Welton ML (2003) Anal neoplasia. Sem Colon Rectal Surg 14:111-118

63. Arbesman H, Ransohoff DF (1987) Is Bowens disease a predictor for the development of internal malignancy? A methodological critique of the literature. JAMA 257:516-518

64. Wieland U, Brockmeyer NH, Weissenborn SJ et al (2006) Imiquimod treatment of anal intraepithelial neoplasia in HIV-positive men. Arch Dermatol 142:1438-1444

65. Bargman H, Hochman J (2003) Topical treatment of Bowen's disease with 5-fluorouracil. J Cutan Med Surg 7:101-105

66. Webber J, Fromm D (2004) Photodynamic therapy for carcinoma in situ of the anus. Arch Surg 139:259-261

67. Pineda CE, Berry JM, Welton ML (2006) High-resolution anoscopy and targeted treatment of high-grade squamous intraepithelial lesions. Dis Colon Rectum 49:126

68. Chang GJ, Berry JM, Jay N, Palefsky JM, Welton ML (2002) Surgical treatment of high-grade anal squamous intraepithelial lesions: a prospective study. Dis Colon Rectum 45:453-458

69. Goldstone SE, Kawalek AZ, Huyett JW (2005) Infrared coagulator: a useful tool for treating anal squamous intraepithelial lesions. Dis Colon Rectum 48:1042-1054

70. Jay N, Berry JM, Hogeboom CJ, Holly EA, Darragh TM, Palefsky JM (1997) Colposcopic appearance of anal squamous intraepithelial lesions: relationship to histopathology. Dis Colon Rectum 40:919-928

71. Bertram P, Treutner KH, Rubben A, Hauptmann S, Schumpelick V (1995) Invasive squamous-cell carcinoma in giant anorectal condyloma (Buschke-Lowenstein tumor). Langenbecks Arch Chir 380:115-118

72. Garrett K, Kalady MF (2010) Anal neoplasms. Surg Clin North Am 90:147-161 